Décadrages Décadrages

cinéma, à travers champs Cinéma, à travers champs

$10 \mid 2007$

La trilogie de Dieu de João César Monteiro

\title{
La trilogie de Dieu
}

\section{(2) OpenEdition}

1 Journals

Édition électronique

URL : https://journals.openedition.org/decadrages/415

DOI : $10.4000 /$ decadrages. 415

ISSN : 2297-5977

Éditeur

Association Décadrages

Édition imprimée

Date de publication : 10 avril 2007

Pagination : 8

ISBN : 978-2-9700582-5-0

ISSN : 2235-7823

Référence électronique

"La trilogie de Dieu », Décadrages [En ligne], 10 | 2007, mis en ligne le 10 décembre 2012, consulté le 03 avril 2022. URL : http://journals.openedition.org/decadrages/415 ; DOI : https://doi.org/10.4000/ decadrages.415

(B) Décadrages 


\section{La trilogie de Dieu}

Souvenirs de la maison jaune (Recordações da casa amarela, 1989, 120 min.) Scénario, réalisation: João César Monteiro. Image: José António Loureiro. Son: Vasco Pimentel. Production: Invicta Filmes. Interprétation: João César Monteiro (Jean de Dieu), Manuela de Freitas (Dona Violeta), Sabina Sacchi (Mimi, voix de Inês de Medeiros), Teresa Calado (M"le Julieta), Ruy Furtado (M. Armenda), Luís Miguel Cintra (Livio).

\section{La comédie de Dieu (A Comédia de Deus, 1995, 163 min.)}

Scénario, réalisation: João César Monteiro. Image: Mário Barroso. Son: Rolly Belhassen. Production: Joaquim Pinto, Martine Marignac, Pierre Grise, La Sept/Arte, Mikado Films, Zentropa Production, G.E.R. Interprétation: João César alias Max Monteiro (Jean de Dieu), Cláudia Teixeira (Joaninha), Raquel Ascensão (Rosarinho), Manuela de Freitas (Judite).

\section{Les noces de Dieu (As Bodas de Deus, 1998, 150 min.)}

Scénario, réalisation: João César Monteiro. Image: Mário Barroso. Son: Joaquim Pinto. Production: Paulo Branco, Madragoa Filmes, Gemini Films, RTP. Interprétation: João César Monteiro (Jean de Dieu), Rita Durão (Joana de Deus), Joana Azevedo (princesse Elena Gombrowicz), José Airosa (prince Omar Rachid), Manuela de Freitas (Mère Bernarda), Luís Miguel Cintra (envoyé de Dieu).

\section{Films adjacents}

\section{Conserva Acabada (1989, 13 min.)}

Scénario, réalisation: João César Monteiro. Image : José António Loureiro. Son: Pedro Caldas. Production: Rita Filmes. Interprétation: João César Monteiro, Alexandra Lencastre.

\section{Le bassin de J. W. (1997, $125 \mathrm{~min}$.}

Scénario, réalisation: João César Monteiro. Image: Mário Barroso. Son: Jean-Claude Laureux. Production: Fábrica de Imagens, Euripide Production, José Mazeda, Daniel Toscan du Plantier, Frédéric Sichler. Interprétation: João César Monteiro alias João o Obscuro alias Jean Watan (Dieu, Max Monteiro, Henrique, Jean de Dieu), Hugues Quester (Jean de Dieu, Lucifer), Pierre Clémenti (Paul, Henrique), Joana Azevedo (Catarina, Ariane), Manuela de Freitas (une prostituée).

\section{Va-et-vient (Vai-e-vem, 2003, 179 min.)}

Scénario, réalisation: João César Monteiro. Image: Mário Barroso. Son: Jean-Claude Laureux. Production: Paulo Branco, Madragoa Filmes, Gemini Films, RTP, Arte France Cinéma. Interprétation: João César Monteiro (Jean Vuvu), Rita Pereira Marques (Adriana, Urraca), Joaquina Chichau (M"e Custódia), Manuela de Freitas (Fausta), Lígia Soares (Narcisa), José Mora Ramos (M. Zé Aniceto), Rita Durão (Jacinta), Maria do Carmo Rôlo (Barbra la policière), Miguel Borges (Jorge Valera Vuvu). 